\title{
Pannexin 1: The Molecular Substrate of Astrocyte "Hemichannels"
}

\author{
Rodolfo Iglesias, ${ }^{1}$ Gerhard Dahl, ${ }^{2}$ Feng Qiu, ${ }^{2}$ David C. Spray, ${ }^{1}$ and Eliana Scemes ${ }^{1}$ \\ ${ }^{1}$ The Dominick P. Purpura Department of Neuroscience, Albert Einstein College of Medicine, Bronx, New York 10461, and ${ }^{2}$ Department of Physiology and \\ Biophysics, University of Miami, Miami, Florida 33136
}

\begin{abstract}
Purinergic signaling plays distinct and important roles in the CNS, including the transmission of calcium signals between astrocytes. Gap junction hemichannels are among the mechanisms proposed by which astrocytes might release ATP; however, whether the gap junction protein connexin43 (Cx43) forms these "hemichannels" remains controversial. Recently, a new group of proteins, the pannexins, have been shown to form nonselective, high-conductance plasmalemmal channels permeable to ATP, thereby offering an alternative for the hemichannel protein. Here, we provide strong evidence that, in cultured astrocytes, pannexin1 (Panx1) but not Cx43 forms hemichannels. Electrophysiological and fluorescence microscope recordings performed in wild-type and Cx43-null astrocytes did not reveal any differences in hemichannel activity, which was mostly eliminated by treating Cx43-null astrocytes with Panx1-short interfering RNA [Panx1-knockdown (Panx1-KD)]. Moreover, quantification of the amount of ATP released from wild-type, Cx43-null, and Panx1-KD astrocytes indicates that downregulation of Panx1, but not of $\mathrm{Cx} 43$, prevented ATP release from these cells.
\end{abstract}

\section{Introduction}

It has been widely proposed that connexin 43 (Cx43), the main gap junction protein expressed in astrocytes, can under specific conditions form functional "hemichannels," providing a transmembrane pathway for the diffusion of ions and relatively large molecules (for review, see Spray et al., 2006; Harris, 2007). Evidence in support is primarily pharmacological, showing blockade of uptake of fluorescent dyes (Lucifer yellow, ethidium bromide, propidium iodide) and of release of intracellular molecules (ATP, glutamate) by compounds known to block gap junction channels; additionally, electrophysiological recordings have demonstrated the presence of large $(>200 \mathrm{pS}$, as expected for $\mathrm{Cx} 43$ hemichannels) conductance channels in astrocytes (Contreras et al., 2003; Retamal et al., 2007).

Recently, a newly discovered group of proteins, the pannexins (Panx1, -2, and -3), were cloned from mammalian tissues. Pannexins were classified as gap junction proteins because of their significant but low $(\sim 20 \%)$ homology to the innexins, the gap junction proteins of invertebrates; they bear no sequence homology with connexins, the gap junction proteins of chordates (for review, see Scemes et al., 2007).

It is becoming apparent that none of the pannexins readily forms intercellular channels (but see Bruzzone et al., 2003) and that Panx1 in particular forms functional plasmalemmal chan-

Received Dec. 19, 2008; revised March 8, 2009; accepted March 30, 2009.

This work was supported by National Institutes of Health Grants NS052245 (E.S.), GM-8610 (G.D.), and NS041282 (D.C.S.). We gratefully acknowledge the technical assistance of Aisha Cordero with cell cultures and mouse genotyping.

Correspondence should be addressed to Dr. Eliana Scemes, The Dominick P. Purpura Department of Neuroscience, Albert Einstein College of Medicine, Kennedy Center, Room 203, 1410 Pelham Parkway, Bronx, NY 10461. E-mail: scemes@aecom.yu.edu.

DOI:10.1523/JNEUROSCI.6062-08.2009

Copyright $\odot 2009$ Society for Neuroscience $\quad$ 0270-6474/09/297092-06\$15.00/0 nels that display properties similar to those that have been attributed to connexin hemichannels (for review, see Dahl and Locovei, 2006; Spray et al., 2006; Scemes et al., 2009).

In the CNS, Panx1 mRNA and protein were reported to be present in both neuronal and glial cells in vivo and in vitro (Ray et al., 2005, 2006; Huang et al., 2007a). Panx1 forms large conductance (400-500 pS) nonselective channels that are permeable to ATP, carboxyfluorescein, and YoPro (Bao et al., 2004; Locovei et al., 2006b, 2007) and are sensitive to compounds known to block connexin channels, including carbenoxolone (CBX), flufenamic acid, and mefloquine (MFQ) (Bruzzone et al., 2005; Iglesias et al., 2008).

Because the overlapping pharmacology reported for pannexins and connexins may confound identification of the molecular substrate of hemichannel activity in astrocytes, we have compared the electrophysiological properties and membrane permeability to dyes of astrocytes prepared from wild-type (WT) and Cx43-null neonatal mice. We here show for the first time that cultured astrocytes display functional Panxl channels that are activated by membrane depolarization or after $\mathrm{P}_{2} \mathrm{X}_{7}$ receptor $\left(\mathrm{P} 2 \mathrm{X}_{7} \mathrm{R}\right)$ stimulation. These channels are sensitive to $\mathrm{CBX}$ and MFQ and allow permeation by YoPro and ATP. Because no differences in the activation properties of hemichannels were observed between wild-type and $\mathrm{Cx} 43$-null astrocytes and because Panx1 short interfering RNA (siRNA) reduces the occurrence of these channels, we conclude that Panx1 is more likely the molecular substrate for hemichannel activity in these cells.

\section{Materials and Methods}

Astrocyte cultures. We used primary cultures of cortical astrocytes derived from neonatal WT and Cx43-null mice (offspring of Cx43 heterozygotes in C57BL/6J-Gjal strain; at least two litters per experiment were used). Animals were maintained at the Albert Einstein College of Medicine; the Albert Einstein College of Medicine Animal Care and Use Committee has 
approved all experimental procedures used in these studies. Cortices were separated from whole-brain embryos [embryonic day 19 (E19) to E20], and after meninges removal, tissues were trypsinized (0.1\% trypsin at $37^{\circ} \mathrm{C}$ for $10 \mathrm{~min}$ ). Cells from each animal were collected by centrifugation and pellet suspended in DMEM supplemented with 10\% FBS and $1 \%$ antibiotics and seeded in $60 \mathrm{~mm}$ culture dishes. Genotype of individual cultures was determined by PCR on tail DNA (Dermietzel et al., $2000)$. Astrocytes were maintained for $2-3$ weeks in culture $(100 \%$ humidity; $95 \%$ air, $5 \% \mathrm{CO}_{2} ; 37^{\circ} \mathrm{C}$ ) at which time $\sim 95-98 \%$ of the cells were immunopositive for glial fibrillary acidic protein.

Electrophysiology. Solitary WT and Cx43-null astrocytes were plated on coverslips $24-48 \mathrm{~h}$ before recordings. Whole-cell patch-clamp recordings were performed as previously described (Iglesias et al., 2008). Briefly, cells were bathed in external solution containing the following (in mM): $147 \mathrm{NaCl}, 10$ HEPES, 13 glucose, $2 \mathrm{CaCl}_{2}, 1 \mathrm{MgCl}_{2}$, and $5 \mathrm{KCl}, \mathrm{pH}$ 7.4. The pipette solution contained the following (in $\mathrm{mm}$ ): $130 \mathrm{CsCl}, 10$ EGTA, $10 \mathrm{HEPES}, 0.5 \mathrm{CaCl}_{2}$. Activation of Panxl channels by voltage was performed using a $10 \mathrm{~s}$ ramp protocol from holding a potential of -60 to $+100 \mathrm{mV}$. To analyze the participation of Panxl channels in agonistinduced $\mathrm{P} 2 \mathrm{X}_{7} \mathrm{R}$ activation, astrocyte membrane potential was held at -60 $\mathrm{mV}$ and the $\mathrm{P} 2 \mathrm{X}_{7} \mathrm{R}$ agonist 3-O-(4-benzoyl)benzoyl adenosine trisphosphate (BzATP) $(50 \mu \mathrm{M})$ was superfused for $5-10 \mathrm{~s}$, a condition that was subthreshold for total activation of Panxl channels. After the first response to the agonist, the gap junction channel blockers CBX $(50 \mu \mathrm{M})$ and MFQ (100 nM) were superfused for $5 \mathrm{~min}$ before the addition of the P2R agonist. Electrophysiological recordings were accomplished using an Axopatch 200B amplifier, and pClamp9 software was used for data acquisition and analysis.

Dye uptake. Astrocytes (WT and Cx43-null) plated on glass-bottom dishes (MatTek) were bathed for $5 \mathrm{~min}$ in phosphate-buffered solution, $\mathrm{pH} 7.4$, containing the cell-impermeant dye YoPro-1 (5 $\mu \mathrm{M})$. Cells were then exposed to a solution containing $300 \mu \mathrm{M}$ BzATP and $5 \mu \mathrm{M}$ of the dye. (Higher concentrations of agonist than those used in the electrophysiological studies are necessary for long-lasting and full activation of Panx1 channels and for optimal detection of YoPro fluorescence.) YoPro fluorescence intensity was measured during $500 \mathrm{~s}$ BzATP stimulation, as previously described (Suadicani et al., 2006). The effects of a gap junction channel blocker (MFQ, $10 \mathrm{nM}$ ) and of a $\mathrm{P} 2 \mathrm{X}_{7}$ receptor antagonist [brilliant blue $\mathrm{G}(\mathrm{BBG}), 1 \mu \mathrm{M}$ ] on BzATP-induced dye uptake were also tested. YoPro fluorescence was captured using a CoolSNAP-HQ2 CCD camera (Photometrics) attached to an inverted Nikon microscope (Eclipse TE-2000E) equipped with a $20 \times$ dry objective and FITC filter set using Metafluor software.

Panx1 siRNA. Astrocytes were treated with $50 \mathrm{~nm}$ small interference RNA corresponding to the mouse pannexin 1 sequence, as well as with scrambled sequences, using $6 \mu \mathrm{l} / 1.5 \mathrm{ml}$ oligofectamine reagent (Invitrogen), as previously described (Locovei et al., 2007). After overnight exposure, transfection reagents were removed and cells incubated for $30 \mathrm{~h}$ in DMEM-FBS medium before use in electrophysiological and dye uptake studies.

ATP release. Confluent cultures of WT and Cx43-null astrocytes plated in $35 \mathrm{~mm}$ dishes were washed twice in PBS, and then exposed for 3 min to PBS containing $300 \mu \mathrm{M}$ BzATP. After complete removal and washout of the agonist, cells were bathed in PBS for $2 \mathrm{~min}$ before collection of samples of BzATP-induced ATP release. (Agonist concentration and incubation times are based on dye uptake measurements and were optimal for detection of released ATP.) For measurements of intracellular ATP levels, cells were lysed with Tris-buffered solution containing 1\% Triton X-100 and supernatants of whole-cell lysates were used. The amount of ATP in samples were measured as previously described (Striedinger et al., 2007), using the luciferin/luciferase assay (Invitrogen) and a plate reader luminometer (Veritas; Turner Instruments). The amounts of ATP in the samples were calculated from standard curves and normalized for the protein concentration, using the BCA assay (Pierce).

\section{Results}

Wild-type and Cx43-null astrocytes in culture express functional Panx1 channels

Whole-cell recordings from solitary astrocytes indicated the presence of voltage-activated outward currents in WT cells; the cur-
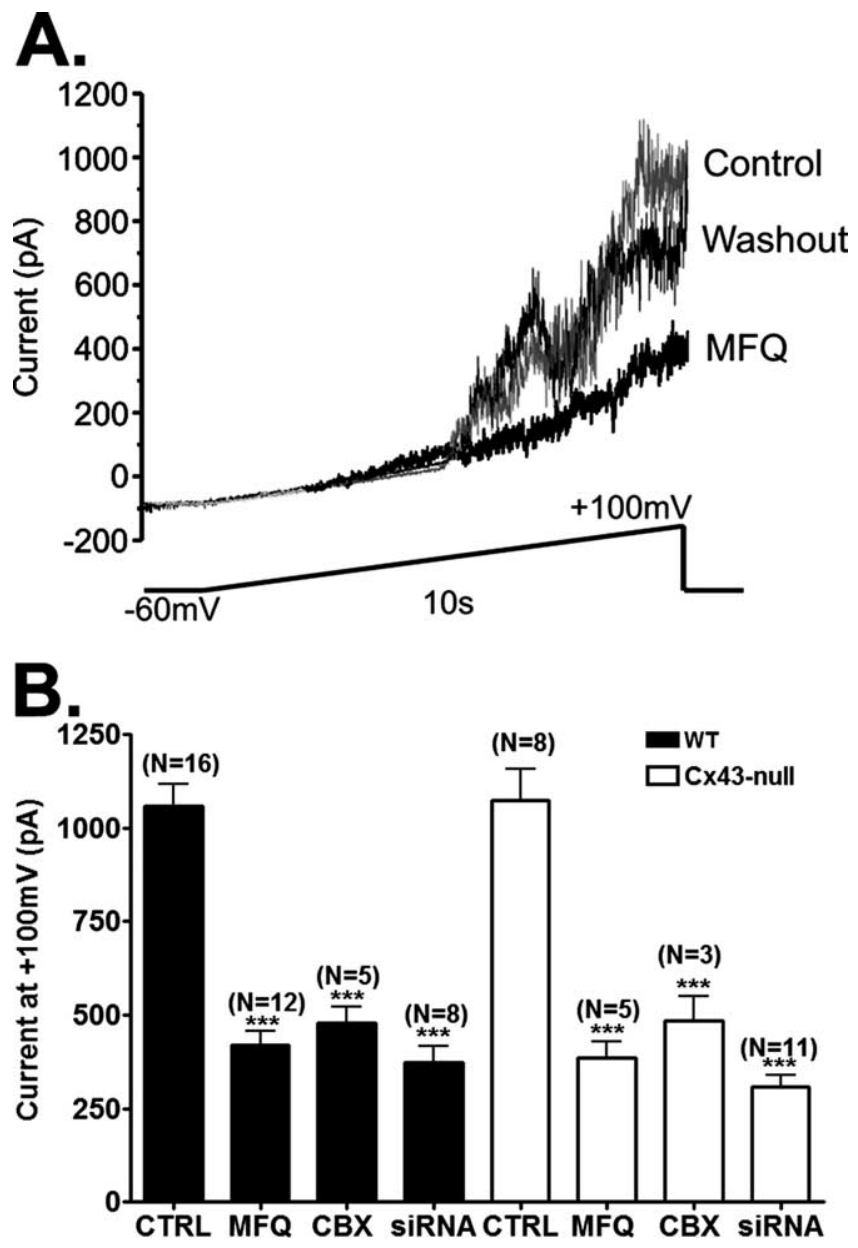

Figure 1. Effects of gap junction channel blockers on voltage-activated Panx1 currents in astrocytes. $A$, Examples of outward currents recorded from a single astrocyte in the absence and presence of MFQ (100 nM) and after MFQ washout. Currents were obtained in response to voltage ramps ( -60 to $+100 \mathrm{mV}$ ) with $-60 \mathrm{mV}$ holding membrane potential. $\boldsymbol{B}$, Bar histograms showing the mean \pm SE values of current amplitudes at the end of the current ramps $(+100 \mathrm{mV})$ recorded from WT (black bars) and (x43-null (white bars) astrocytes bathed in control (CTRL) solution and solutions containing CBX (50 $\mu \mathrm{m})$ and MFQ (100 nM). Current amplitudes obtained for astrocytes treated for $48 \mathrm{~h}$ with Panx 1 siRNA are shown in the last bars. The numbers in parentheses correspond to the number of cells tested. ${ }^{* *} p<0.01$.

rent amplitudes increased at voltages above $+20 \mathrm{mV}$ and were significantly attenuated by CBX and MFQ, two compounds previously described to block Panx 1 channels more effectively than connexin gap junction channels (Cruikshank et al. 2004; Bruzzone et al., 2005; Iglesias et al., 2008). At membrane potentials of $+100 \mathrm{mV}$, current amplitudes (1062.0 $\pm 60.6 \mathrm{pA} ; N=16$ cells $)$ were significantly reduced by $61 \%(419.0 \pm 38.2 \mathrm{pA} ; N=12$ cells) and by $55 \%(478.9 \pm 41.6 \mathrm{pA} ; N=5$ cells $)$ after exposure to $100 \mathrm{~nm}$ MFQ and $50 \mu \mathrm{M} \mathrm{CBX}$, respectively $(p<0.01$, ANOVA followed by Dunnett's test) (Fig. 1).

To verify that channel activity recorded in WT astrocytes was not attributable to activation of currents attributed to Cx43 hemichannels (Contreras et al., 2003; Retamal et al., 2007; Kang et al., 2008), we performed electrophysiological recordings as described above using cortical astrocytes derived from Cx43-null mice. Similarly to what we found for WT astrocytes, Cx43-null cells displayed voltage-activated outward currents (Fig. $1 \mathrm{~B}$ ). At membrane potentials of $+100 \mathrm{mV}$, current amplitudes (1074.0 $\pm 84.1 \mathrm{pA} ; N=8$ cells) recorded from Cx43-null cells were significantly reduced by $64 \%(386.7 \pm 41.1 \mathrm{pA} ; N=5$ cells $)$ 
and $55 \%(485.5 \pm 62.5 \mathrm{pA} ; N=3$ cells $)$ after exposure to MFQ (100 nM) and CBX $(50 \mu \mathrm{M})$, respectively $(p<0.01$, ANOVA followed by Dunnett's test). The amplitudes of voltage-activated currents measured in Cx43-null astrocytes (1074.0 \pm $84.1 \mathrm{pA} ; N=8$ cells) were virtually identical with those recorded from WT cells $(1062.0 \pm 60.6 \mathrm{pA} ; N=16$ cells; $p=0.89$, $t$ test). These data, summarized in Figure $1 B$, indicate that the channels contributing this outward current at positive potentials are not $\mathrm{Cx} 43$ hemichannels.

To obtain evidence for the molecular identity of CBX- and MFQ-sensitive outward currents, we treated astrocytes with Panxl siRNA. Under the condition of Panx1-knockdown (Panx1-KD), voltageactivated currents recorded from both WT and Cx43-null astrocytes were greatly attenuated. After 48-72 h Panx1-KD, current amplitudes measured at $+100 \mathrm{mV}$ were significantly reduced to $308.0 \pm 31.1$ $\mathrm{pA}(N=11 \mathrm{Cx} 43$-null cells $)$ and to $373.8 \pm 42.5 \mathrm{pA}(N=8 \mathrm{WT}$ cells $)$ compared with those of untreated $(1062.0 \pm$ $60.6 \mathrm{pA} ; N=16$ cells; $p<0.01, t$ test) (Fig. $1 B)$ or scrambled Panx1 siRNA-treated $(1028.0 \pm 89.4 \mathrm{pA} ; N=$ 9 cells) (supplemental Fig. S1, available at www.jneurosci.org as supplemental material) WT astrocytes. Exposure of Panx1-KD Cx43-null astrocytes to MFQ (100 nM) did not further attenuate voltage-activated outward currents $(230.2 \pm 24.2 \mathrm{pA} ; N=5$ cells; $p>0.05, t$ test). These data strongly suggest that Panx 1 forms the channels responsible for current activation at positive potentials in astrocytes. [Evidence that Panx1 but not $\mathrm{Cx} 43$ forms nonjunctional channels in Xenopus oocytes is shown in supplemental Fig. S2 (available at www.jneurosci.org as supplemental material).]

Panx1 channels in wild-type and Cx43-null astrocytes are activated by stimulation of $\mathrm{P} 2 \mathrm{X}_{7}$ receptors

Activation of $\mathrm{P} 2 \mathrm{X}_{7}$ receptors by high ATP concentration and by the synthetic agonist BzATP leads to opening of Panxl channels in a macrophage cell line and in Xenopus oocytes coexpressing these two proteins (Pelegrin and Surprenant, 2006; Locovei et al., 2007; Iglesias et al., 2008).

As illustrated in Figure 2A, $5 \mathrm{~s}$ exposure to BzATP $(50 \mu \mathrm{M})$ elicited inward currents in astrocytes held at $-60 \mathrm{mV}$. The inward current elicited by BzATP was biphasic, with an initial small inward current followed by a larger one; the second but not the first component was blocked by $100 \mathrm{~nm}$ MFQ (BzATP, $470.6 \pm$ 18.9 pA; $N=10$ cells; MFQ, $130.8 \pm 17.3$ pA, $N=8$ cells; $p<$ $0.001, t$ test) (Fig. $2 A, B$ ). The remaining MFQ-insensitive currents are likely mediated by flux of ions through the cation channel of the $\mathrm{P} 2 \mathrm{X}_{7} \mathrm{R}$ receptor itself, as we have recently shown for the J774 macrophage cell line (Iglesias et al., 2008).

Similarly to WT astrocytes, the second phase of BzTAPinduced currents (458.2 $\pm 15.7 \mathrm{pA} ; N=5$ cells) in Cx43-null astrocytes was also significantly decreased $(131.6 \pm 25.4 \mathrm{pA} ; N=$ 4 cells; $p<0.01, t$ test) by 100 nM MFQ (Fig. 2C,D). Knockdown of Panxl greatly attenuated BzATP-induced currents in Cx43null $(238.9 \pm 40.0 \mathrm{pA} ; N=5$ cells $)$ and in WT astrocytes $(202.5 \pm$ $30.10 \mathrm{pA} ; N=6$ cells), compared with untreated (470.6 \pm 18.9 pA; $N=10$ cells; $p<0.001, t$ test) (Fig. $2 B, D$ ) and scrambled
Panx1 siRNA-treated $(431.6 \pm 30.1 \mathrm{pA} ; N=7$ cells) (supplemental Fig. S1, available at www.jneurosci.org as supplemental material) WT cells.

Wild-type and $\mathrm{Cx} 43$-null astrocytes are equally permeable to YoPro after BzATP stimulation

To evaluate the contribution of Panx1 to astrocyte membrane permeabilization, we exposed astrocytes to BzATP and measured the influx of YoPro-1. As we previously showed for WT spinal cord astrocytes (Suadicani et al., 2006), BzATP induced YoPro uptake in WT and Cx43-null cortical astrocytes that was prevented by BBG, MFQ, and by Panx1 siRNA (Fig. $3 A, B$ ). After $500 \mathrm{~s}$ exposure to $300 \mu \mathrm{M}$ BzATP, YoPro fluorescence intensity increased $1.14 \pm 0.005$-fold $(N=72$ cells) in WT astrocytes and $1.14 \pm 0.004$-fold $(N=90$ cells $)$ in Cx43-null cells. Five minute preincubation with BBG $(1 \mu \mathrm{M})$ reduced YoPro uptake in WT ( $1.05 \pm 0.002 ; N=90$ cells) as well as in Cx43-null (1.02 \pm 0.003 ; $N=90$ cells). MFQ (10 nM) also prevented YoPro uptake in both WT $(1.03 \pm 0.003 ; N=90$ cells $)$ and Cx43-null $(1.03 \pm 0.003$; $N=90$ cells) astrocytes. Similarly, knockdown of Panx1 also prevented BzATP-induced YoPro uptake in WT (1.06 \pm 0.001; $N=84$ cells $)$ and in Cx43-null (1.03 $\pm 0.01 ; N=100$ cells) astrocytes (Fig. 3B). Scrambled Panxl siRNA had no effect on BzATP-induced dye uptake from WT astrocytes (1.13 \pm 0.004 ; $N=300$ cells), and there was no YoPro uptake in the absence of BzATP stimulation $(1.03 \pm 0.002 ; N=100$ cells $)$.

Wild-type and $\mathrm{Cx}$ 43-null astrocytes express similar levels of Panx1 and $P 2 X_{7}$ receptors but release different amounts of ATP

To evaluate whether deletion of the Gjal gene affected the expression levels of $\mathrm{P} 2 \mathrm{X}_{7} \mathrm{R}$ and Panx1, Western blot analyses were performed on whole-cell lysates of astrocyte cultures derived from at least three different litters of heterozygous matings. No significant differences in protein expression levels of $\mathrm{P} 2 \mathrm{X}_{7}$ and Panx1 were detected when comparing astrocyte cultures derived from 

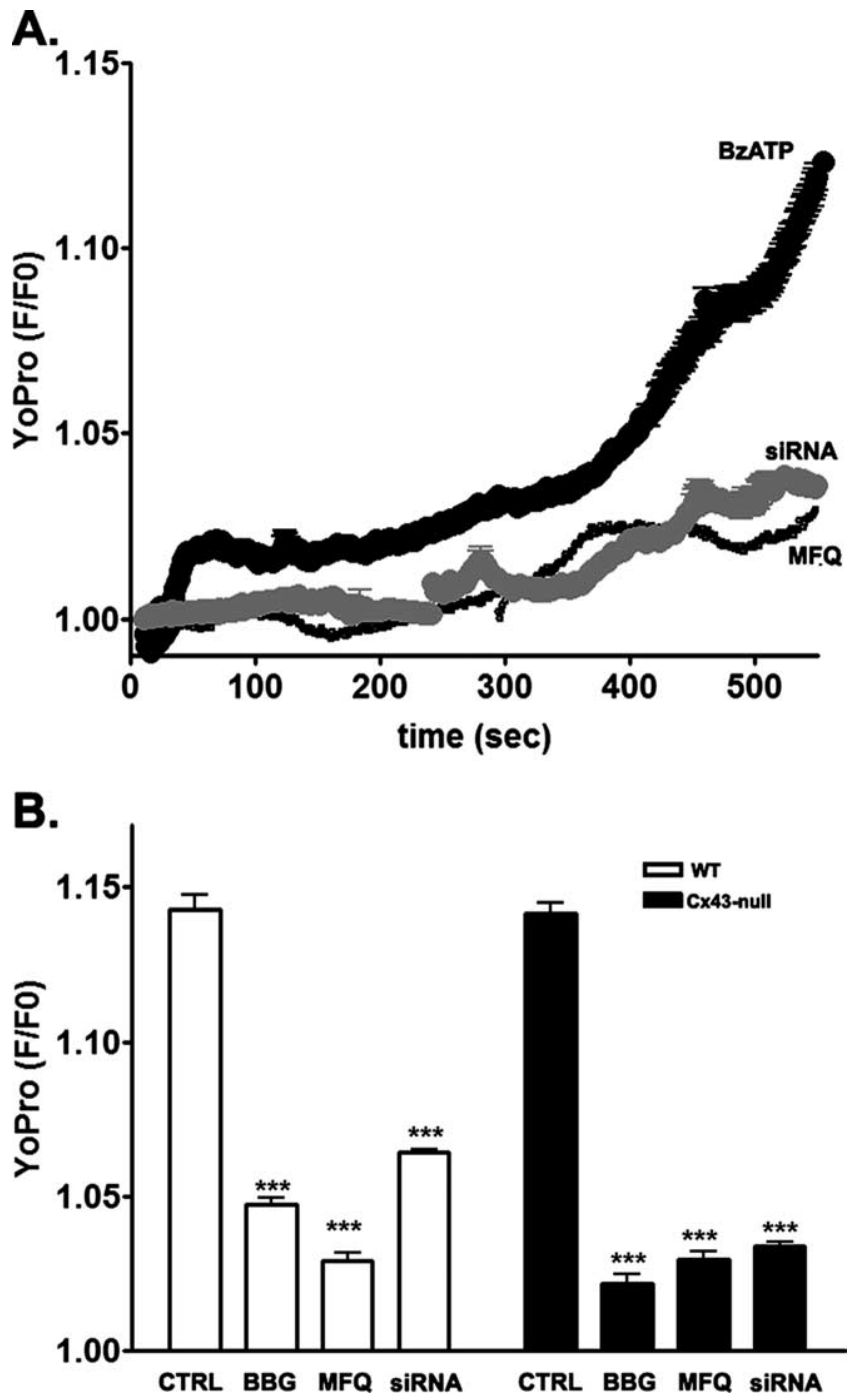

Figure 3. The $P 2 X_{7} R-$ pannexin 1 complex mediates astrocyte membrane permeabilization. $A$, Representative time course of YoPro uptake recorded from WT astrocytes exposed to BzATP $(300 \mu \mathrm{M})$ in the absence and presence of MFQ (100 nM) and after Panx 1 knockdown with siRNA. $B$, Bar histograms showing the mean $\pm S E$ values of the relative YoPro fluorescence intensity obtained for wild-type (white bars) and (x43-null (black bars) astrocytes treated for $500 \mathrm{~s}$ with BzATP (300 $\mu \mathrm{m})$ in the absence and presence of $1 \mu \mathrm{M} \mathrm{BBG}$ and of $100 \mathrm{~nm} \mathrm{MFQ} .{ }^{* * *} p<0.01$.

WT and Cx43-null sibling mice (supplemental Fig. S3, available at www.jneurosci.org as supplemental material). Thus, these results strongly suggest that the persistence of hemichannel currents and membrane permeability to YoPro seen in Cx43-null astrocytes (Figs. 1, 3) are not related to increased expression levels of $\mathrm{P} 2 \mathrm{X}_{7}$ receptors and Panx1 that might in principle compensate for the loss of putative $\mathrm{Cx} 43$ hemichannels.

Using the luciferin-luciferase assay, we recorded significantly lower BzATP-induced ATP release from Cx43-null (119.0 \pm 18.2 $\mathrm{nM} ; N=7$ experiments) compared with WT astrocytes $(205.8 \pm$ $20.5 \mathrm{~nm} ; N=10$ experiments; $p<0.05, t$ test) (Fig. $4 A$ ). However, cytosolic ATP levels in Cx43-null $(6.96 \pm 0.67 \mu \mathrm{M} ; N=7$ experiments) were lower compared with those of WT astrocytes (11.4 $\pm 1.4 \mu \mathrm{M} ; N=8$ experiments; $p<0.05, t$ test) (Fig. $4 B$ ). This result suggests that the lower extracellular ATP levels recorded from Cx43-null astrocytes may reflect their lower cytosolic levels rather than lack of $\mathrm{Cx} 43$ hemichannels.

Nevertheless, in terms of fold of ATP release after receptor stimulation in relation to basal nonstimulated condition, no dif-
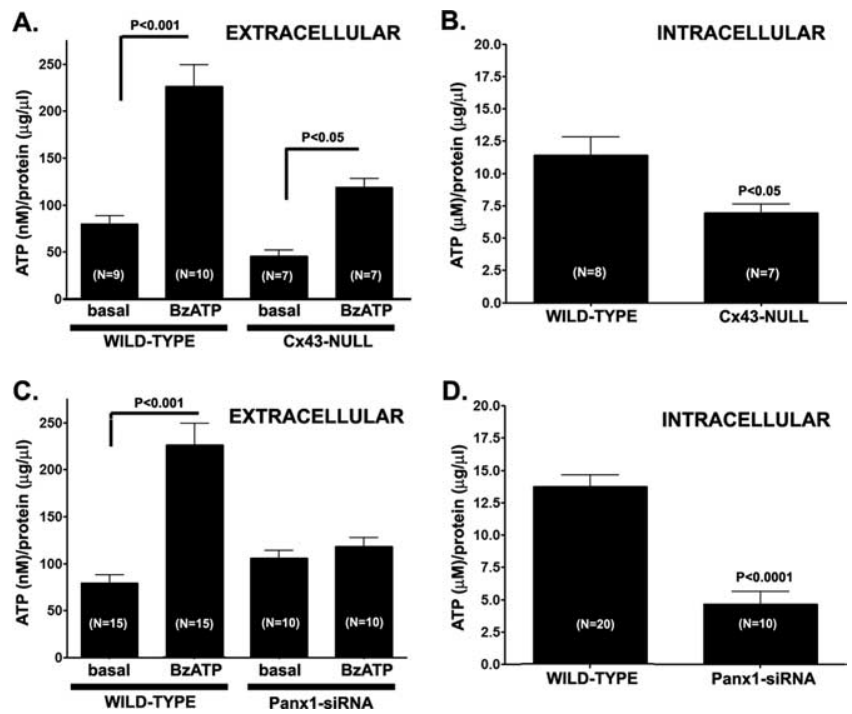

Figure 4. BzATP-induced ATP release from astrocytes. Bar histograms showing the mean \pm SE values of ATP $(\boldsymbol{A}, \boldsymbol{C})$ present in the extracellular solution in response to BzATP prestimulation of WT and (x43-null $(\boldsymbol{A})$ and WT and Panx1-siRNA-treated $(\boldsymbol{C})$ astrocytes. $\boldsymbol{B}$ and $\boldsymbol{D}$ show the mean \pm SE values of intracellular ATP present in the cytosol of WT and $(x 43$-null astrocytes $(\boldsymbol{B})$ and in cells untreated and treated with Panx1-siRNA ( $\boldsymbol{C}$. Note that, in $\boldsymbol{A}$ and $\boldsymbol{C}$, the values of ATP are expressed as nanomolar, and in $\boldsymbol{B}$ and $\boldsymbol{D}$, in micromolar.

ference was found between WT and Cx43-null astrocytes. After BzATP stimulation, a 2.9-fold increase from basal levels was measured in extracellular ATP from cultured WT astrocytes (from $72.23 \pm 7.98 \mathrm{~nm}$ ATP to $205.8 \pm 20.5 \mathrm{~nm} \mathrm{ATP} ; N=9-10$ experiments; $p<0.001, t$ test) (Fig. $4 A$ ). Similarly, a 2.4-fold increase in ATP release was also recorded from $\mathrm{Cx} 43$-null astrocytes after BzATP stimulation (from $49.5 \pm 6.7$ to $119.0 \pm 18.2 \mathrm{~nm} \mathrm{ATP}$; $N=5$ independent experiments) (Fig. $4 A)(p<0.05, t$ test). This result showing similar fold changes in ATP release in both WT and Cx43-null cells provides additional support that the pathway mediating BzATP-induced ATP release is unlikely to be Cx43 hemichannels.

To evaluate whether Panxl could provide the pathway for ATP release from astrocytes, experiments were performed on WT astrocytes untreated and treated with Panx1 siRNA. As shown in Figure 4C, knockdown of Panx1 almost completely prevented BzATP-induced ATP release (from $105.6 \pm 8.24$ to $117.9 \pm 9.9$ $\mathrm{nM} ; N=10$ experiments; $p>0.05, t$ test). Similarly to $\mathrm{Cx} 43$-null astrocytes (Fig. 4B), cytosolic ATP levels in Panx1 siRNAtreated WT cells $(4.7 \pm 0.9 \mu \mathrm{M} ; N=10$ experiments $)$ were also significantly lower $(p<0.001, t$ test $)$ than in untreated astrocytes (13.7 $\pm 0.9 \mu \mathrm{M} ; N=20$ experiments) (Fig. $4 D)$. Scrambled Panx1 siRNA reduced cytosolic ATP levels (from $20.7 \pm$ 0.8 to $13.3 \pm 0.5 \mu \mathrm{M} ; N=3$ experiments; $p<0.0001, t$ test) but did not prevent BzATP-induced ATP release from WT astrocytes (from $53.8 \pm 9.0$ to $101.5 \pm 1.4 \mathrm{~nm} ; N=3$ experiments; $p=0.0004, t$ test $)$.

Together, these results support the hypothesis that Panx1 and not $\mathrm{Cx} 43$ hemichannels provides a pathway for ATP release from astrocytes.

\section{Discussion}

Communication among astrocytes themselves and with other neural cells relies not only on direct gap junctional contacts but is also mediated through the release of paracrine signals. Among the distinct mechanisms by which astrocytes release "gliotransmitters," hemichannels formed of gap junction (con- 
nexin) or gap junction-like (pannexin) proteins have been suggested to be prominent under certain conditions (for review, see Parpura et al., 2004; Dahl and Locovei, 2006; Spray et al., 2006; Scemes et al., 2007).

Connexin43 is the most abundant gap junction protein in astrocytes (Dermietzel et al., 2000; Scemes et al., 2000) and openings of $\mathrm{Cx} 43$ hemichannels have been proposed to account for glial release of ATP (Stout et al., 2002; Kang et al., 2008) and glutamate (Ye et al., 2003) as well as for the uptake of fluorescent molecules under ischemic and inflammatory conditions (Contreras et al., 2002; Retamal et al., 2007). Evidence presented favoring the involvement of $\mathrm{Cx} 43$ in these processes includes blockade by compounds that inhibit $\mathrm{Cx} 43$ gap junction channels, presence of channels with appropriately large unitary conductances $(\sim 200 \mathrm{pS})$ in membranes of astrocytes and transfected cells (Retamal et al., 2007) (for review, see Spray et al., 2006). The strongest evidence favoring $\mathrm{Cx} 43$ hemichannels came from exogenous expression of GFP (green fluorescent protein)-tagged $\mathrm{Cx} 43$, in which channel properties reflected the presence of the tag (Bukauskas et al., 2002; Contreras et al., 2003). Interestingly, metabolic inhibition-induced membrane permeabilization was prevented in $\mathrm{Cx} 43^{\mathrm{de} / \mathrm{del}}$ but not in $\mathrm{Cx} 43^{\mathrm{f} / \mathrm{f}}$ :GFAP-Cre astrocytes (Contreras et al., 2002), suggesting that $90 \%$ loss of $\mathrm{Cx} 43$ does not abolish hemichannel activity.

Pannexin 1 has been reported to form gap junction channels and also to function as hemi-gap junction channels that are sensitive to gap junction channel blockers, including carbenoxolone and flufenamic acid (Bruzzone et al., 2003, 2005). The nonjunctional Panx1 channels (pannexons) are voltage sensitive, 400$500 \mathrm{pS}$ channels that have been reported to be modulated by intracellular calcium and by mechanical stretch (Bao et al., 2004; Locovei et al., 2006a); these large conductance channels have been proposed to mediate ATP release from erythrocytes, mouse taste buds, and astrocytes (Locovei et al., 2006b; Huang et al., 2007b; Scemes et al., 2007). Panx1 can be activated by ATP through the metabotropic $\mathrm{P}_{2} \mathrm{Y}_{1}$ and $\mathrm{P} 2 \mathrm{Y}_{2}$ receptors (Locovei et al., 2006a), as well as through the ionotropic P2 $\mathrm{X}_{7}$ receptors (Pelegrin and Surprenant, 2006; Locovei et al., 2007; Iglesias et al., 2008).

Panxl transcripts are found in astrocytes in vitro and in vivo (Ray et al., 2005, 2006; Huang et al., 2007a); however, the extent to which the Panx1 protein forms functional channels in astroglial cells and their properties has not yet been fully investigated. We here show that Panx 1 channels likely perform the hemichannel function in astrocytes. This is based on our quantitative measurements showing no difference between outward currents activated by strong depolarization or by $\mathrm{P} 2 \mathrm{X}_{7}$ receptor stimulation in WT compared with Cx43-null astrocytes. Moreover, knockdown of Panxl by siRNA is shown to greatly reduce the occurrence of these currents. In addition, MFQ, which has been previously shown not to block $\mathrm{Cx} 43$ gap junction channels at concentrations $<20 \mu \mathrm{M}$ (Cruikshank et al., 2004) and to block Panx1 channels at much lower concentration (Iglesias et al., 2008), is here shown to prevent both voltage-activated and BzATP-induced currents in both WT and Cx43-null astrocytes.

We previously showed that the $\mathrm{P} 2 \mathrm{X}_{7} \mathrm{R}-\mathrm{Panx} 1$ complex provides sites of ATP release, amplifying the extent to which intercellular $\mathrm{Ca}^{2+}$ waves (ICWs) spread among WT and Cx43-null astrocytes when exposed to low divalent cation solution (Suadicani et al., 2006; Scemes et al., 2007). In contrast to this view are the reports showing that the amount of ATP released from cells correlates with the levels of $\mathrm{Cx} 43$ expression and that gap junction channel blockers attenuate ATP release from astrocytes and transfected C6 glioma cells (Cotrina et al., 1998; Stout et al., 2002; Kang et al., 2008). However, to our knowledge, no previous study has directly measured ATP levels in WT and Cx43-null astrocytes. In agreement with these previous reports, we also found a correlation between $\mathrm{Cx} 43$ expression levels and amount of ATP release. However, we attributed this difference to lower cytoplasmic ATP concentration in Cx43-null astrocytes rather than to inhibited release in the absence of $\mathrm{Cx} 43$ hemichannels. Moreover, because knockdown of Panxl prevented ATP release, it is more likely that Panx 1 and not $\mathrm{Cx} 43$ hemichannels can provide sites of ATP release that amplifies the distance to which calcium signals spread among astrocytes. This possibility is in agreement with our previous studies showing that knockdown of Panx1, but not of Cx43, prevented the amplification of intercellular calcium waves in astrocytes (Suadicani et al., 2006; Scemes et al., 2007).

In summary, our results strongly support the notion that Panx1 and not $\mathrm{Cx} 43$ is the main molecular substrate of hemichannel. This is evidenced by the similar hemichannel activity measured in WT and Cx43-null astrocytes and by the prevention of such activity after Panx1 knockdown.

\section{References}

Bao L, Locovei S, Dahl G (2004) Pannexin membrane channels are mechanosensitive conduits for ATP. FEBS Lett 572:65-68.

Bruzzone R, Hormuzdi SG, Barbe MT, Herb A, Monyer H (2003) Pannexins, a family of gap junction proteins expressed in brain. Proc Natl Acad Sci U S A 100:13644-13649.

Bruzzone R, Barbe MT, Jakob NJ, Monyer H (2005) Pharmacological properties of homomeric and heteromeric pannexin hemichannels expressed in Xenopus oocytes. J Neurochem 92:1033-1043.

Bukauskas FF, Bukauskiene A, Verselis VK (2002) Conductance and permeability of the residual state of connexin43 gap junction channels. J Gen Physiol 119:171-185.

Contreras JE, Sánchez HA, Eugenin EA, Speidel D, Theis M, Willecke K, Bukauskas FF, Bennett MV, Sáez JC (2002) Metabolic inhibition induces opening of unapposed connexin 43 gap junction hemichannels and reduces gap junctional communication in cortical astrocytes in culture. Proc Natl Acad Sci U S A 99:495-500.

Contreras JE, Sáez JC, Bukauskas FF, Bennett MV (2003) Gating and regulation of connexin $43(\mathrm{Cx} 43)$ hemichannels. Proc Natl Acad Sci U S A 100:11388-11393.

Cotrina ML, Lin JH, Alves-Rodrigues A, Liu S, Li J, Azmi-Ghadimi H, Kang J, Naus CC, Nedergaard M (1998) Connexins regulate calcium signaling by controlling ATP release. Proc Natl Acad Sci U S A 95:15735-15740.

Cruikshank SJ, Hopperstad M, Younger M, Connors BW, Spray DC, Srinivas M (2004) Potent block of Cx36 and Cx50 gap junction channels by mefloquine. Proc Natl Acad Sci U S A 101:12364-12369.

Dahl G, Locovei S (2006) Pannexin: to gap or not to gap, is that a question? IUBMB Life 58:409-419.

Dermietzel R, Gao Y, Scemes E, Vieira D, Urban M, Kremer M, Bennett MV, Spray DC (2000) Connexin43 null mice reveal that astrocytes express multiple connexins. Brain Res Brain Res Rev 32:45-56.

Harris AL (2007) Connexin channel permeability to cytoplasmic molecules. Prog Biophys Mol Biol 94:120-143.

Huang Y, Grinspan JB, Abrams CK, Scherer SS (2007a) Pannexin1 is expressed by neurons and glia but does not form functional gap junctions. Glia 55:46-56.

Huang YJ, Maruyama Y, Dvoryanchikov G, Pereira E, Chaudhari N, Roper SD (2007b) The role of pannexin 1 hemichannels in ATP release and cell-cell communication in mouse taste buds. Proc Natl Acad Sci U S A 104:6436-6441.

Iglesias R, Locovei S, Roque A, Alberto AP, Dahl G, Spray DC, Scemes E (2008) $\mathrm{P} 2 \mathrm{X}_{7}$ receptor-Pannexin 1 complex: pharmacology and signaling. Am J Physiol Cell Physiol 295:C752-C760.

Kang J, Kang N, Lovatt D, Torres A, Zhao Z, Lin J, Nedergaard M (2008) Connexin 43 hemichannels are permeable to ATP. J Neurosci 28:4702-4711.

Locovei S, Wang J, Dahl G (2006a) Activation of pannexin 1 channels by ATP through P2Y receptors and by cytoplasmic calcium. FEBS Lett 580:239-244 
Locovei S, Bao L, Dahl G (2006b) Pannexin 1 in erythrocytes: function without a gap. Proc Natl Acad Sci U S A 103:7655-7659.

Locovei S, Scemes E, Qiu F, Spray DC, Dahl G (2007) Pannexinl is part of the pore forming unit of the $\mathrm{P} 2 \mathrm{X}_{7}$ receptor death complex. FEBS Lett 581:483-488

Parpura V, Scemes E, Spray DC (2004) Mechanisms of glutamate release from astrocytes: gap junction "hemichannels," purinergic receptors and exocytotic release. Neurochem Int 45:259-264.

Pelegrin P, Surprenant A (2006) Pannexin-1 mediates large pore formation and interleukin-1beta release by the ATP-gated P2X7 receptor. EMBO J 25:5071-5082.

Ray A, Zoidl G, Weickert S, Wahle P, Dermietzel R (2005) Site specific and developmental expression of pannexin1 in the mouse nervous system. Eur J Neurosci 21:3277-3290.

Ray A, Zoidl G, Wahle P, Dermietzel R (2006) Pannexin expression in the cerebellum. Cerebellum 5:189-192.

Retamal MA, Froger N, Palacios-Prado N, Ezan P, Sáez PJ, Sáez JC, Giaume C (2007) Cx43 hemichannels and gap junction channels in astrocytes are regulated oppositely by proinflammatory cytokines released from activated microglia. J Neurosci 27:13781-13792.

Scemes E, Suadicani SO, Spray DC (2000) Intercellular communication in spinal cord astrocytes: fine tuning between gap junctions and P2 nucleotide receptors in calcium wave propagation. J Neurosci 20:1435-1445.

Scemes E, Suadicani SO, Dahl G, Spray DC (2007) Connexin and pannexin mediated cell-cell communication. Neuron Glia Biol 3:199-208.

Scemes E, Spray DC, Meda P (2009) Connexins, pannexins, innexins: novel roles of "hemi-channels." Pflugers Arch 457:1207-1226.

Spray DC, Ye ZC, Ransom BR (2006) Functional connexin "hemichannels": a critical appraisal. Glia 54:758-773.

Stout CE, Costantin JL, Naus CC, Charles AC (2002) Intercellular calcium signaling in astrocytes via ATP release through connexin hemichannels. J Biol Chem 277:10482-10488.

Striedinger K, Meda P, Scemes E (2007) Exocytosis of ATP from astrocyte progenitors modulates spontaneous $\mathrm{Ca}^{2+}$ oscillations and cell migration. Glia 55:652-662.

Suadicani SO, Brosnan CF, Scemes E (2006) P2X $\mathrm{X}_{7}$ receptors mediate ATP release and amplification of astrocytic intercellular $\mathrm{Ca}^{2+}$ signaling. J Neurosci 26:1378-1385.

Ye ZC, Wyeth MS, Baltan-Tekkok S, Ransom BR (2003) Functional hemichannels in astrocytes: a novel mechanism of glutamate release. J Neurosci 23:3588-3596. 